\section{Estratégias de retórica e enquadramento na cobertura do segundo mandato de Dilma Rousseff pelas revistas semanais brasileiras}

[Rhetorical and framing strategies by Brazilian weekly magazines on coverage of Dilma Rousseff's second term]

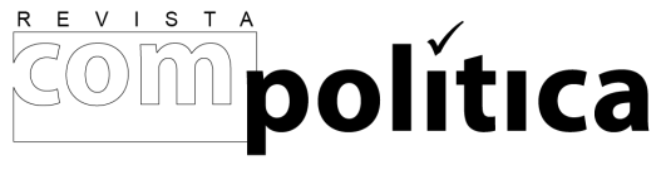

revista compolítica 2017, vol. 7(1)

compolitica.org/revista ISSN: $2236-4781$

DOI: 10.21878/compolitica.2017.7.1.273 (2)pen Access Journal

\author{
Marcos Paulo da Silva \\ Universidade Federal de Mato Grosso do Sul \\ [Federal University of Mato Grosso do Sul]

\section{Raquel de Souza Jeronymo} \\ Universidade Federal de Mato Grosso do Sul \\ [Federal University of Mato Grosso do Sul]
}

\begin{abstract}
Resumo
Este texto volta-se à matriz de referências da framing analisys para estudar o modo como duas das maiores revistas semanais brasileiras - Veja e IstoÉ - valem-se de estratégias retóricas para estabelecerem enquadramentos noticiosos semelhantes na cobertura do primeiro ano do segundo mandato da presidenta Dilma Rousseff. Como recorte empírico, o trabalho debruça-se sobre as edições dos meses de janeiro e dezembro de 2015, período marcado por uma profunda crise política envolvendo o Governo Federal brasileiro. Conclui-se que o tratamento realizado pelas revistas semanais estudadas, sobretudo em seus processos de seleção de fontes, hierarquização de informações e utilização de figuras retóricas, aproxima-se de um modelo de enquadramento noticioso hegemônico nos termos trabalhados por Gitlin (2003), Porto (2002), Sigal (1974) e Soley (1992), tais como: a simplificação, a dramatização, o silenciamento de atores políticos e a constituição de um padrão hegemônico das fontes
\end{abstract}

Palavras-chave: jornalismo; enquadramento noticioso; estratégias retóricas; Dilma Rousseff.

\begin{abstract}
The article uses the framing analysis references in order to study how two of the largest Brazilian weekly magazines - Veja and IstoÉ - employ rhetorical strategies to similarly frame their news coverage of the first year of the second term of President Dilma Rousseff. As empirical frame, the study focuses on the issues of January and December, 2015, a period marked by a deep political crisis involving the Brazilian federal government. It can be concluded that the approach of the two weekly magazines, especially in their sources selection processes, hierarchy of information and use of rhetorical figures, resembles a hegemonic news framing model such as those employed by Gitlin (2003), Porto (2002), Sigal (1974) and Soley (1992), such as: simplification, dramatization, muting of political actors and construction of a hegemonic pattern of sources.
\end{abstract}

Keywords: journalism, news framing; rhetorical strategies; Dilma Rousseff. 


\section{Estratégias de retórica e enquadramento na cobertura do segundo mandato de Dilma Rousseff pelas revistas semanais brasileiras}

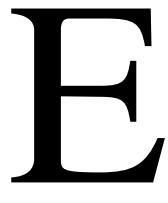

m outubro de 2014, no pleito presidencial mais disputado desde a redemocratização do Brasil, segundo o Tribunal Superior Eleitoral (TSE), a presidenta Dilma Rousseff (PT) foi considerada reeleita no segundo turno com uma vantagem de apenas três pontos percentuais em relação a seu então oponente, o senador mineiro Aécio Neves (PSDB), diferença materializada em cerca de 3,4 milhões de votos. O fato político gerado, dentre outros aspectos, pela pequena diferença de votos e pela reação imediata da coligação derrotada (que manifestou o desejo de formalizar um pedido de recontagem de votos) culminou num cenário político de acirradas disputas programáticas e simbólicas pela agenda política do país, agravadas por denúncias de corrupção em diversos âmbitos, investigações de grande repercussão - como a Comissão Parlamentar de Inquérito (CPI) sobre a Petrobras e a Operação Lava Jato -, além de uma crise econômica que provocou a desvalorização do Real, o aumento dos juros para conter a inflação e o rebaixamento do grau de investimento do Brasil por grandes agências internacionais de crédito.

Nessa conjuntura, os veículos de comunicação tradicionais, ao lado da força mobilizadora crescente resultante das redes sociais na Internet, protagonizaram movimentos de “interpretação, apresentação, seleção, ênfase e exclusão de informações” (Gitlin, 2003, p.7) que resultaram em enquadramentos noticiosos peculiares para a história política recente do país. Os doze meses de 2015, primeiro ano do segundo mandato de Dilma Rousseff, compreendem, assim, um período de turbulência que sucede as apertadas eleições presidenciais de 2014 e antecede a abertura do processo de impeachment levado a cabo pelo legislativo brasileiro no primeiro semestre de $2016^{1}$.

\footnotetext{
${ }^{1}$ O despacho do então presidente da Câmara dos Deputados, Eduardo Cunha (PMDB), autorizando a abertura do impeachment, ocorreu no dia 2 de dezembro de 2015, mesma data em que a bancada do PT no legislativo anunciou o
} 
Este artigo volta-se a um quadro de referências teórico-metodológicas próprio da framing analisys (Entman, 1993; Goffman, 2012; Gitlin, 2003; Kuypers, 2009) para estudar o modo como duas das principais revistas semanais brasileiras - Veja, do Grupo Abril, e IstoÉ, da Editora Três - valeram-se de estratégias retóricas como a simplificação, a dramatização, o silenciamento de atores políticos e a utilização de fontes não identificadas para estabelecerem seus enquadramentos noticiosos na cobertura política do período.

Por opção metodológica, adotou-se como recorte empírico os exemplares do primeiro e do último mês de 2015 de cada revista, de maneira a analisar os enquadramentos realizados pelos periódicos no início e no final do primeiro ano do segundo mandato de Dilma Rousseff.

Do ponto de vista do alcance, Veja e IstoÉ remetem a uma tiragem média somada de 1 milhão e 400 mil exemplares segundo dados da Associação Nacional de Editores de Revistas (ANER). Levou-se em consideração para a escolha das revistas, além da tiragem, o fato de constituírem as mais antigas dentre os três periódicos com maior circulação média no país (Veja, Época e IstoÉ) e também a ampla relevância que o assunto teve em ambos os veículos, que dedicaram mais de 50\% de suas capas ao longo do ano para tratar de assuntos relacionados diretamente ou indiretamente à presidenta ${ }^{2}$. Em números absolutos, Veja mencionou ou retratou a presidenta Dilma Rousseff em 17 de suas 52 capas ao longo do ano, mas o total sobe para 27 se consideradas também as

voto pela continuidade do processo de cassação do peemedebista no Conselho de Ética da Câmara. A decisão de Cunha foi interpretada como retaliação pela equipe política de Dilma Rousseff, que sempre apresentou o argumento de que nunca houve indícios que caracterizassem o crime de responsabilidade. Existia ainda nos bastidores políticos um clima de que o avanço das investigações contra a corrupção poderia avançar para outros atores e partidos políticos para além daqueles presentes formalmente na base de apoio do Palácio do Planalto. O próprio PMDB, partido do então vicepresidente Michel Temer, havia rompido com o Governo Federal e recebido apoio de partidos de oposição, como o PSDB e o DEM. Em 31 de agosto de 2016, após um tumultuado processo de julgamento político e nove meses após o aceite da denúncia pela Presidência da Câmara dos Deputados, a sentença final do afastamento de Dilma Rousseff, publicada pelo então presidente do Senado, Renan Calheiros, afirmara: "No dia 02 de dezembro de 2015, a Presidência da Câmara dos Deputados recebeu e autuou a Denúncia por Crime de Responsabilidade (DCR) n 1 , de 2015, oferecida por Miguel Reale Júnior, Hélio Pereira Bicudo e Janaína Conceição Paschoal, subscrita pelo Advogado Flávio Henrique Costa Pereira contra a Excelentíssima Senhora Presidente da República, Dilma Vana Rousseff, atribuindo-lhe a prática, em tese, dos crimes de responsabilidade tipificados no art. 85, V, VI e VII, da Constituição Federal, e art. 4, V e VI, art. 9, itens 3 e 7, art. 10, itens 6 a 9 e art. 11, item 3, todos da Lei 1.079/1950" (Brasil, 2016).

2 Faz-se pertinente mencionar que há uma vasta literatura na comunicação política brasileira que analisa o comportamento das revistas semanais no processo de construção do campo jornalístico. Tal literatura se apresenta desde a década de 1990 e aponta que esses periódicos se colocam como formadores de opinião da classe média brasileira ao assumirem explicitamente posicionamentos frente à agenda política do país. Dentre essas leituras, ver, por exemplo, as discussões de Soares (1999), Azevedo (2004), Prado (2005) e Miguel \& Biroli (2008). 
capas relacionadas a Luís Inácio Lula da Silva, ex-presidente e aliado político, e ao Partido dos Trabalhadores (PT), o que representa 52\% do total de edições. No caso da IstoÉ, são 20 capas direcionadas a Dilma e mais 10 a Lula e ao PT, totalizando $60 \%$ do total de revistas em 2015.

Ao todo, somadas as edições dos dois periódicos escolhidos, foram analisados 16 exemplares das revistas. De Veja, foram estudadas nove edições, quatro do mês de janeiro e cinco do mês de dezembro. De IstoÉ foram sete exemplares, três de janeiro e quatro de dezembro. O semanário da Editora Três conta com um número menor de exemplares, pois não houve circulação da revista nas semanas dos dias 07 de janeiro e 30 de dezembro de 2015.

Ainda no terreno do recorte empírico, além do mapeamento geral, optou-se por analisar de modo verticalizado uma matéria de cada edição, adotando-se como critérios de seleção os parâmetros de proeminência (a recorrência de menções a Dilma Rousseff como agente principal no conjunto de matérias sobre o cenário político brasileiro) e de relevância (destaque do assunto no contexto geral de matérias da edição). São marcadores de relevância o fato de a matéria figurar ou não na capa da revista, a quantidade de páginas que ela ocupa na edição e a quantidade de vezes que Dilma Rousseff é mencionada ou retratada na matéria.

Finalmente, como forma de viabilizar o estudo de enquadramento noticioso, foram considerados alguns pressupostos e concepções já sedimentados no campo das Ciências Humanas e Sociais, particularmente nas pesquisas em Comunicação, tal como a superação dos paradigmas jornalísticos da objetividade e da imparcialidade (Entman, 1993; Gans, 2004; Gitlin, 2003; Kuypers, 2009; Porto, 2002; Schudson, 2010; Traquina, 2008). Tais conceitos, paradoxalmente, são ainda disseminados pelo discurso de autolegitimação da prática jornalística (Gomes, 2009), conforme verificado na manifestação das políticas editoriais dos dois periódicos estudados. A pesquisa buscou compreender também os mecanismos - técnicos e simbólicos - que podem ocultar a difusão de tais concepções. 


\section{Fontes e canais de informação como recursos retóricos}

Adotando-se como base teórico-metodológica a perspectiva da framing analysis para verificar o modo como as revistas Veja e IstoÉ estabelecem suas estratégias retóricas na construção e na formatação do conteúdo noticioso, observamos os mecanismos de seleção, silenciamento e ênfase de fontes e de canais de informação. A análise das fontes utilizadas nas matérias examinadas baseia-se no estudo extensivo desenvolvido por Leon Sigal (1974, Reporters and Officials) no cenário político norte-americano e no conceito de canais de informação. Para o autor, são os "caminhos pelos quais as informações atingem o repórter" (Sigal, 1974, p. 120, tradução nossa), classificados em três categorias: de rotina, informais e corporativos.

$\mathrm{Na}$ primeira categoria, "canais de rotina", estão inclusos procedimentos oficiais, comunicados e coletivas de imprensa, palestras, cerimônias e outros tipos de eventos nãoespontâneos. Os "canais informais" incluem, por exemplo, vazamentos, processos nãogovernamentais, reuniões de associações ou convenções sindicais e também matérias publicadas em outros veículos de imprensa. Finalmente, os "canais corporativos" são compreendidos como as entrevistas e as apurações realizadas por iniciativa dos próprios repórteres, eventos nos quais os jornalistas testemunham em primeira mão e as conclusões ou análises tomadas nesse processo (Sigal, 1974). Por fim, uma última modalidade, denominada aqui como canal "não identificado", constitui-se a partir de uma tradução livre para a expressão "not as certainable”, utilizada por Sigal (1974) para se referir a situações em que não é possível determinar o canal utilizado para a obtenção da informação analisada.

Outra categoria de análise das fontes noticiosas utilizadas por Veja e IstoÉ baseia-se nos conceitos traçados por Lawrence Soley (1992), que divide as fontes em duas classificações: os "news makers", que participam ativamente dos eventos noticiosos, e os “news shapers”, que são procurados pela mídia na busca por “informações privilegiadas, panos de fundo ou previsões sobre o resultado das histórias que ainda estão em desdobramento" (Soley, 1992, p. 2, tradução nossa). Classificam-se como "news makers" as chamadas "fontes primárias" e como "news shapers" as "fontes secundárias", uma vez 
que se entende que os conceitos utilizados por Lage (2005) para as fontes primárias e secundárias se alinham aos utilizados por Soley (1992).

Apesar de considerados concorrentes no segmento das revistas semanais, os dois veículos utilizaram critérios muitos semelhantes na escolha das fontes e dos canais de informação. Nas edições analisadas, os canais mais utilizados foram o de rotina e o corporativo, mas destacam-se as ocorrências nas quais o canal de informação não pôde ser identificado, representando $30 \%$ do total das fontes em ambas as publicações. As fontes oficiais (atores políticos pertencentes à esfera nacional ou regional, autoridades e órgãos ligados ao governo, dentre outros) foram as mais acessadas por meio do "canal de rotina". No caso da Veja, a distribuição entre fontes primárias e secundárias prioriza o primeiro grupo, com 63\%, contra 37\% dos chamados "news shapers" (Soley, 1992). Já nas edições da revista IstoÉ, a distribuição foi bem equilibrada, com aproximadamente $54 \%$ de fontes primárias e $46 \%$ de secundárias.

Os canais de informação localizados na análise empírica das revistas rementem à seguinte disposição (Tabela 1)

Tabela 1 - Canais de informação das matérias analisadas da revista Veja.

\begin{tabular}{l|l|l}
\hline Canais de informação & Ocorrências & Percentual \\
\hline Rotina & 28 & $38,8 \%$ \\
\hline Informal & 3 & $4,1 \%$ \\
\hline Corporativo & 19 & $26,3 \%$ \\
\hline Não identificado & 22 & $30,5 \%$ \\
\hline Total & 72 & $100 \%$ \\
\hline
\end{tabular}

Fonte: Elaboração própria, baseada no modelo elaborado por Sigal (1974). 
Tabela 2 - Canais de informação das matérias analisadas da revista IstoÉ.

\begin{tabular}{l|l|l}
\hline Canais de informação & Ocorrências & Percentual \\
\hline Rotina & 14 & $22,5 \%$ \\
\hline Informal & 10 & $16,1 \%$ \\
\hline Corporativo & 19 & $30,6 \%$ \\
\hline Não identificado & 19 & $30,6 \%$ \\
\hline Total & 62 & $100 \%$ \\
\hline
\end{tabular}

Fonte: Elaboração própria, baseada no modelo elaborado por Sigal (1974).

Pode-se identificar que o "canal corporativo" - entrevistas e pesquisas realizadas por iniciativa dos próprios repórteres - foi utilizado por ambos os veículos em mais de $85 \%$ das vezes para dar voz a fontes secundárias, "especialistas" consultados para analisar, embasar e comentar informações da matéria. O "canal informal" foi utilizado para apresentar citações diretas e indiretas extraídas de redes sociais, vazamentos de informações ou dados oriundos de outros veículos midiáticos, sendo a última uma prática recorrente na revista IstoÉ. Outra prática que evidencia o enquadramento adotado nas matérias analisadas é a utilização de fontes cujo canal de procedência não é explicitado, bem como de fontes não identificadas. São exemplos dessa estratégia retórica as expressões "assessores próximos a Dilma", "um dos conselheiros da presidente" (matéria “Eles disseram não para Dilma", edição no 2355 de 21/01/2015, revista IstoÉ), "facções petistas"; "colaborador próximo ao parlamentar"; e "antigo auxiliar de Dilma" (matérias "Mandato novo, problemas velhos", "A testemunha" e "Impeachment não é guerra", edições no 2407 de 07/01/2015, 2454 de 02/12/2015 e 2455 de 09/12/2015, revista Veja).

Analisando a divisão entre fontes primárias e secundárias, encontra-se uma diferença importante entre as duas categorias. No caso das fontes primárias que figuram nas matérias analisadas, em mais de $60 \%$ dos casos as citações são indiretas. Já no caso das fontes secundárias a situação se inverte, com mais de $60 \%$ de ocorrências com citações diretas. A desigualdade apresentada entre citações diretas e indiretas desequilibra consideravelmente o quadro na medida em que - em uma perspectiva retórica reconhece-se que a representação direta da fala possui uma densidade simbólica de 
veracidade maior do que sua menção indireta, pois, entre outros aspectos, esta última redunda num risco maior de edições e enquadramentos, voluntários ou não, do(s) jornalista(s) que redige $(\mathrm{m})$ e edita(m) a matéria.

Quanto às fontes secundárias, no caso da revista IstoÉ, de modo geral, pode-se dizer que todos os atores políticos mencionados se posicionam de alguma forma no espectro de oposição ao governo de Dilma Rousseff. Nenhum ator político do partido da presidenta, o PT, foi ouvido pela revista, e a menção indireta ao então presidente do partido, Rui Falcão, na matéria “A pior travessia”, da edição no 2401 de 09/12/2015, refere-se apenas a uma nota oficial. Dentre as fontes secundárias sem cargos eletivos, vale destacar a presença do jurista Miguel Reale Jr., um dos signatários do pedido de impeachment de Dilma Rousseff, e de Kim Kataguiri, coordenador do Movimento Brasil Livre (MBL), uma das entidades responsáveis por organizar protestos em todo o país por meio das redes sociais na Internet, com reivindicações de impeachment e acusações diretas ao expresidente Luiz Inácio Lula da Silva e ao Partido dos Trabalhadores.

Já entre as fontes ouvidas pela revista Veja, apenas duas são relacionadas diretamente ao campo das disputas políticas eleitorais: notadamente, o senador e presidente do PSDB, Aécio Neves, candidato derrotado por Dilma Rousseff no segundo turno das eleições para a Presidência da República de 2014; e Marina Silva, fundadora do partido Rede Sustentabilidade, que também foi candidata nas eleições de 2014. Não obstante, a pesquisa exploratória identifica que, como advertira Soley (1992), mesmo fontes sem cargos políticos eletivos e apresentadas muitas vezes sob a alcunha de "analistas" especialistas ou experts, para utilizar a nomenclatura da tradição norte-americana passam ao largo de posições que poderiam ser identificadas como isentas, desinteressadas e/ou objetivas. O economista Sergio Vale, por exemplo, mencionado pela revista Veja apenas como "economista-chefe da consultoria MB Associados", utilizado como fonte secundária em duas matérias ${ }^{3}$ afirmara em entrevista concedida ao site InfoMoney, no dia 01 de março de 2015, que via de modo otimista os "70\% de chances" da saída de Dilma. Já o cientista político Rubens Figueiredo publicara artigo em parceria com Fernando

\footnotetext{
${ }^{3}$ As promessas e a realidade", edição n ${ }^{\circ} 2409$, de 21 de janeiro de 2015, e "De volta ao passado", edição n 2456, de 16 de dezembro de 2015.
} 
Henrique Cardoso, presidente do Brasil por dois mandatos e filiado ao PSDB, partido que fazia oposição destacada a Dilma Rousseff.

Os dados respaldam a conclusão de Lawrence Soley (1992) de que, apesar de os "news shapers" serem muitas vezes apresentados como analistas isentos, "não há nenhuma razão para acreditar que eles são imparciais e objetivos" (Soley, 1992, p. 19, tradução nossa). Em seu estudo sobre as fontes jornalísticas no contexto da imprensa dos Estados Unidos, o autor conclui que o grupo de especialistas consultados pelos jornalistas é muito estreito, sendo constituído de aproximadamente 90 indivíduos em todo o território norteamericano. Esse pressuposto respalda em certa medida os resultados obtidos pela presente análise. Por meio de um levantamento exploratório identificou-se que, dos doze “especialistas" elencados tanto nas matérias da Veja como da IstoÉ, onze puderam ser encontrados com facilidade no mesmo período como fontes em matérias de pelo menos cinco outros veículos de mídia.

\section{Simplificação, amplificação e personificação como estratégias argumentativas}

Outra manifestação do cenário de representação resultante das escolhas editoriais adotadas por Veja e IstoÉ no período analisado relaciona-se com a utilização de estratégias argumentativas típicas da retórica, a exemplo do emprego de figuras de linguagem e de técnicas de argumentação que "cumprem a função de redefinir um determinado campo de informação, criando efeitos novos e que sejam capazes de atrair a atenção do receptor" (Citelli, 2003, p.19-20).

Numa aproximação teórica com o campo dos estudos do jornalismo, nota-se que autores como Traquina (2008) e Wolf (2003) optam por tratar tais estratégias argumentativas no interior do escopo conceitual dos chamados valores-notícia, denominando-os de "valoresnotícia de construção". Tal abordagem é problematizada por outros autores, a exemplo de Gislene Silva (2005), que vincula a concepção de valores-notícia ao plano pragmático dos fenômenos ao passo em que as demais etapas da cadeia de construção e de hierarquização 
noticiosa se estabelecem no circuito mais amplo da noticiabilidade. Shoemaker \& Cohen (2006), por seu turno, interpretam a concepção de noticiabilidade como um constructo de natureza eminentemente cognitiva, o que coloca o conceito de "valor" em uma perspectiva mais próxima do entendimento de Herbert Gans (2004) dos valores noticiosos como valores ideológicos compartilhados nas salas de redação.

De um vértice metodológico, todavia, reconhece-se que as categorias denominadas por Traquina (2008) e Wolf (2003) como "valores-notícia de construção"4 são factíveis para a análise dos recursos de enquadramento adotados por Veja e IstoÉ. Nesse sentido, a "simplificação" ou o fato de o acontecimento ser desprovido de ambiguidade e complexidade (exemplificado por Traquina (2008, p. 91) como o "uso de clichês, estereótipos e ideias feitas") pode ser aqui relacionada com o estudo das fontes. Notou-se que ambas as revistas não lançam mão da prática de apontar o contraditório (mesmo que seja a partir do chamado "outro lado"), o que resulta justamente na simplificação - ou no esvaziamento da complexidade - das perspectivas apresentadas pelo material noticioso.

Outras categorias mencionadas por Traquina (2008), como a "amplificação" (ou seja, "quanto mais amplificado é o acontecimento", mais possibilidades tem a notícia de ser notada, quer seja pela amplitude do ato ou por suas consequências) ou a "relevância" (que refere-se à habilidade do jornalista de construir sua narrativa de modo a conceder um valor simbólico ao acontecimento como se este apresentasse uma relevância única para todas as pessoas), estabelecem-se como estratégias retóricas identificadas em matérias como "Que país teremos?” (IstoÉ, edição no 2402; Figura 1), que deixa implícita que a saída de Dilma Rousseff seria a solução salvadora para todos os problemas políticos e econômicos instaurados no Brasil no momento apresentado. Também estão visíveis na matéria "De volta ao passado", que por meio de recursos verbais e não-verbais esvazia a complexidade da questão e vincula num sentido direto a política econômica do Governo Federal (personificado na figura de Dilma) ao retorno de problemas estruturais que já estariam "superados ou sob controle no país", nas palavras do próprio periódico.

\footnotetext{
${ }^{4}$ Embora conceitualmente se estabeleçam menos como valores noticiosos ligados aos acontecimentos no plano dos fenômenos (SILVA, 2005) ou como valores ideológicos compartilhados pelo campo jornalístico (GANS, 2004) e mais como estratégias retóricas.
} 
Figura 1 - Reprodução de matéria revista IstoÉ, 16 de dezembro de 2015

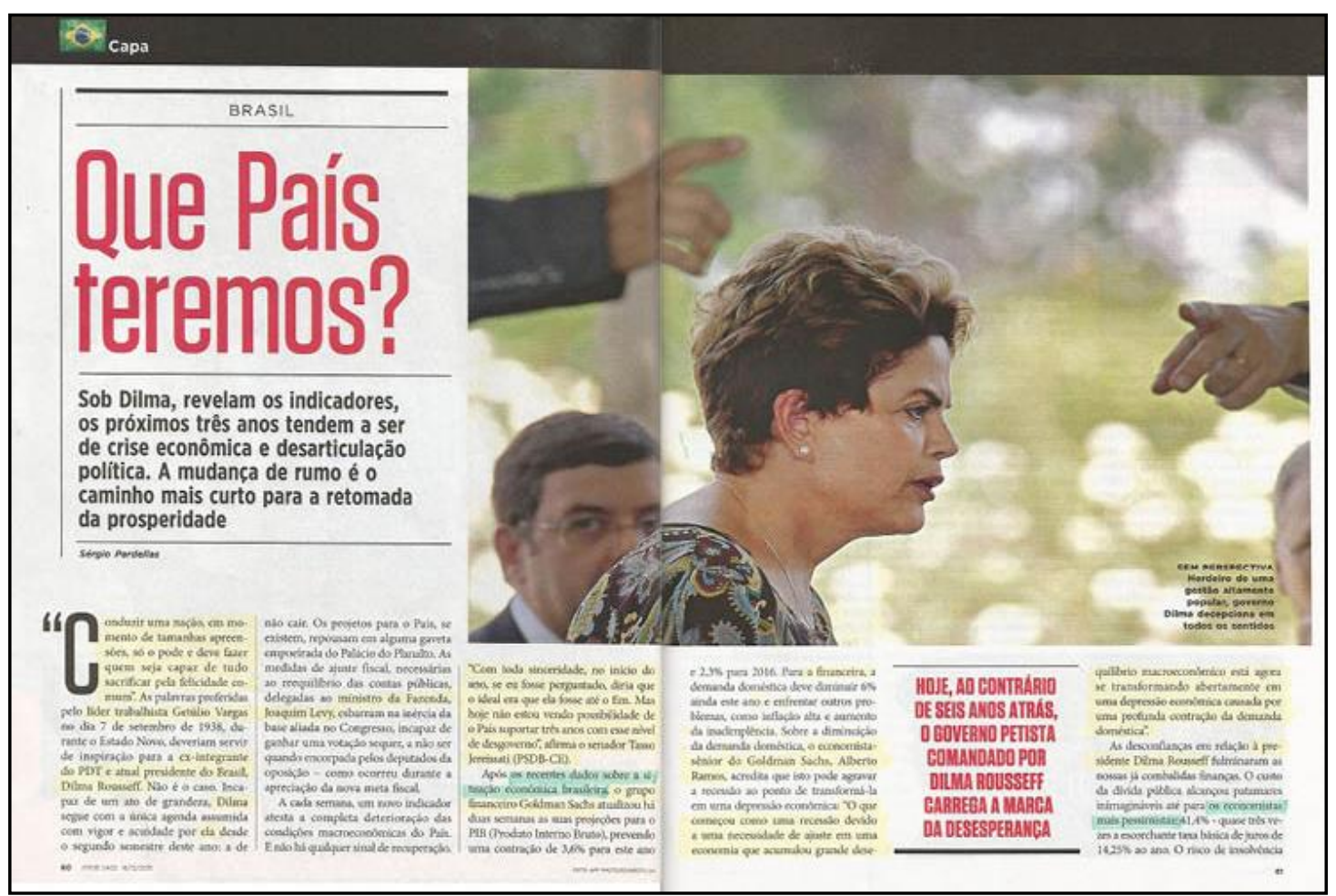

Fonte: Edição nº 2402, 16/12/2015, páginas 60 e 61, revista IstoÉ.

A figura retórica da "personalização", ou a valorização das personas envolvidas no acontecimento em detrimento das problemáticas, manifesta-se na relação que ambas as revistas fazem de todos os entraves políticos e econômicos do país no período em que as matérias foram produzidas com a figura de Dilma Rousseff, cuja imagem aparece em 14 das 16 matérias analisadas, mesmo que o assunto não estivesse diretamente relacionado a ela. De acordo com os veículos, tais entraves não somente são frutos de decisões personalizadas da presidenta, mas de todo seu estafe político e econômico, como ministros, deputados e senadores.

Essa prática vincula-se também ao recurso da "dramatização", ou seja, do reforço do lado emocional para destacar determinados aspectos das notícias, prática sublinhada pelo uso de títulos como "O blecaute de Dilma" (IstoÉ, edição no 2356 de 28/01/2015), em matéria cujo tema era a possibilidade de um racionamento energético no país. O recurso também aparece em “A origem do mal” (Veja, edição no 2457; figura 2), sobre uma operação da 
Polícia Federal que cumpriu mandatos de busca e apreensão em propriedades de vários políticos, sem, no entanto, efetuar prisões ou apresentar conclusões concretas. Por fim, a "consonância" refere-se mais uma vez à prática de inserir acontecimentos em uma "narrativa" mais ampla e já disseminada, relacionada aqui com a crise política e econômica instaurada no Brasil em 2015, pano de fundo para a maior parte das matérias analisadas.

Figura 2 - Reprodução da matéria "A origem do mal"

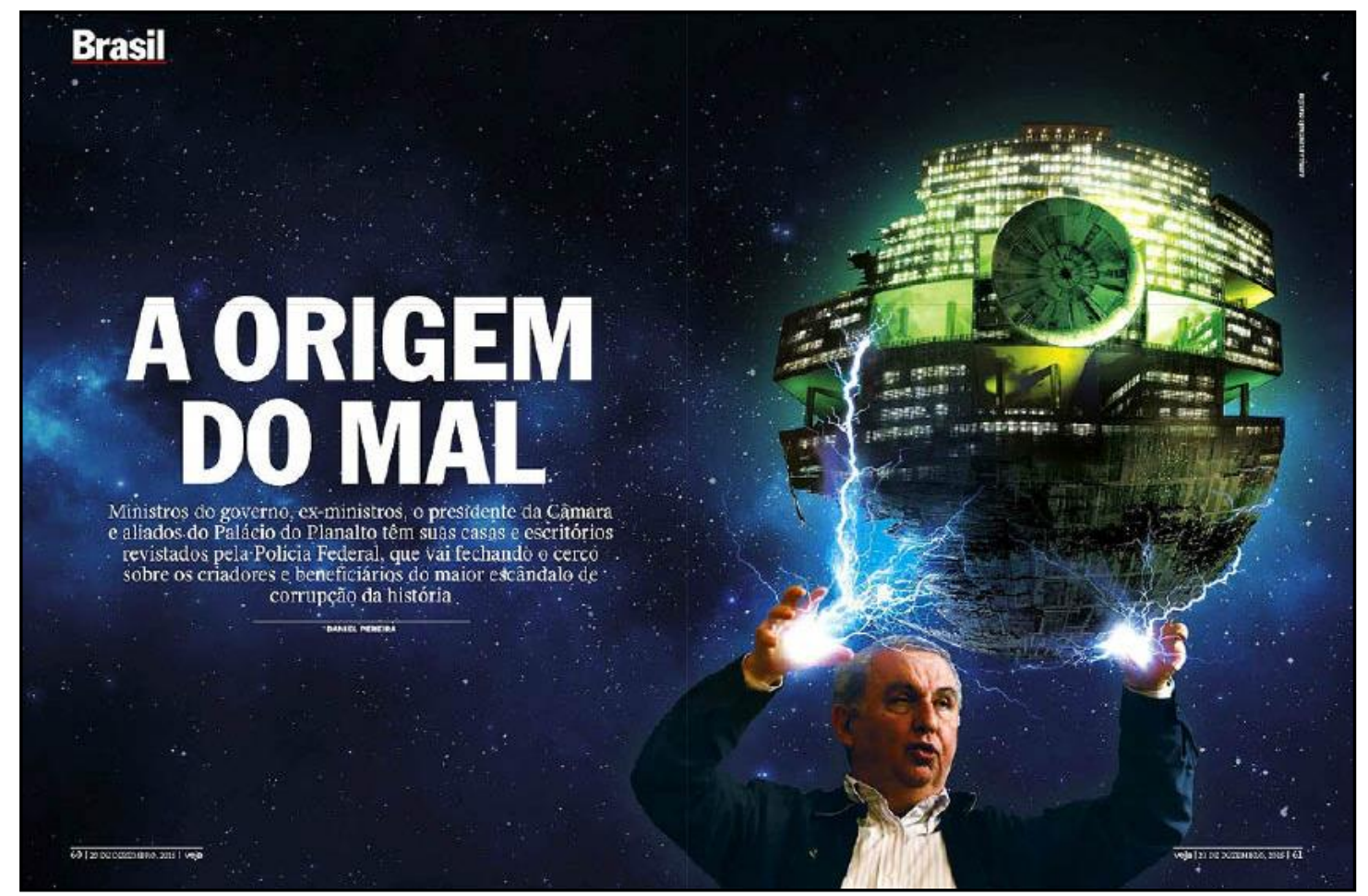

Fonte: Edição no 2457, 23/12/2015, páginas 60 e 61, revista Veja.

Outras narrativas colocadas em consonância são ainda mais explícitas. É o caso da matéria "A origem do mal” (Veja, edição no 2457 de 23/12/2015), cujo elemento gráfico de maior atenção é a fotomontagem utilizada nas páginas 60 e 61, na figura acima. A imagem apresenta o pecuarista José Carlos Bumlai, um ator-chave das investigações conduzidas no período pelo judiciário federal, identificado no texto como "amigo do expresidente Lula". Das mãos do personagem saem raios que se ligam a uma figura que 
remete à "Estrela da Morte", uma estação de batalha utilizada pelo Império Galáctico na série cinematográfica de ficção científica Star Wars, num claro dialogismo com o "lado negro da força" do filme que estampa a capa da edição da referida edição de Veja. No enredo da série cinematográfica, a Estrela da Morte é utilizada pelo grupo que representa o "mal”, numa referência explícita ao título da matéria.

\section{Das estratégias retóricas ao enquadramento noticioso}

As estratégias retóricas identificadas na cobertura do primeiro ano do segundo mandato da presidenta Dilma Rousseff pelas revistas Veja e IstoÉ podem ser interpretadas como manifestações de um modelo peculiar de enquadramento noticioso. Numa perspectiva conceitual, um dos primeiros autores a valer-se da concepção de enquadramento como recurso teórico-metodológico no campo das Ciências Sociais é o sociólogo Erving Goffman, no livro Frame Analysis (1986), traduzido no Brasil como Os quadros da experiência social: uma perspectiva de análise. De acordo com Goffman (2012):

Qualquer acontecimento pode ser descrito em termos de um enfoque que inclui um espectro amplo ou um espectro estreito e (...) em termos de um enfoque em primeiro plano ou distante. E ninguém tem uma teoria sobre qual abertura e qual o nível que serão efetivamente empregados (Goffman, 2012, p.31).

No plano específico da prática jornalística, o sociólogo norte-americano Todd Gitlin, anos mais tarde, cunha algumas das definições até hoje mais referenciadas sobre enquadramento noticioso no livro The Whole World Is Watching, originalmente publicado em 1980. Segundo Gitlin (2003):

Enquadramentos de mídia, largamente silenciados e desconhecidos, organizam o mundo para os jornalistas que os relatam e, em algum grau importante, para nós que dependemos de seus relatos. Enquadramentos de mídia são padrões persistentes de cognição, interpretação e apresentação, de seleção, ênfase e exclusão, pelos quais manipuladores de símbolos rotineiramente organizam 
discursos, sejam verbais ou visuais (Gitlin, 2003, p.7, tradução nossa, itálicos no original).

Longe de serem vistos como práticas inocentes, portanto, os enquadramentos são também considerados instrumentos de poder responsáveis pela construção e manutenção da hegemonia dos modelos econômicos e políticos dominantes (Gitlin, 2003; Porto, 2002). Mauro Porto (2002) problematiza:

Tomando como base os argumentos de Hackett, Tankard (2001, p. 96-97), (...) o conceito de enquadramento oferece um instrumento para examinar empiricamente o papel da mídia na construção da hegemonia, no sentido gramsciano de uma direção intelectual e moral na sociedade civil (Porto, 2002, p.2).

Dessa forma, a partir de uma abordagem política para explicar o que é ou não notícia, Todd Gitlin explicita a noção gramsciana de hegemonia para cunhar o termo "enquadramento hegemônico", definido por ele como "um processo histórico no qual uma imagem de mundo é sistematicamente preterida sobre outras, usualmente através de rotinas práticas” (Gitlin, 2003, p. 257, tradução nossa). Para o sociólogo norte-americano, os enquadramentos hegemônicos são utilizados pelos mantenedores dos meios de comunicação - deliberadamente ou não - para assegurar a manutenção do sistema político e econômico dominante do qual eles mesmos são parte.

O trabalho da hegemonia, apesar de tudo, consiste em impor suposições padronizadas sobre eventos e condições que devem ser "cobertas" pelos preceitos dos padrões de notícias predominantes. (Gitlin, 2003, p. 264, tradução nossa).

Para Murilo Soares (2009, p. 61), “os enquadramentos podem dominar de tal forma o discurso, a ponto de serem tidos como senso comum ou descrições transparentes dos 
fatos, em vez de interpretações". Valendo-se da discussão apresentada por Carragee \& Roefs (2004), o autor afirma que:

Os enquadramentos das elites são geralmente favorecidos, devido a seus recursos econômicos, à centralização da coleta de notícias em instituições e à tendência dos repórteres a atribuir maior credibilidade a fontes oficiais do que aos seus desafiadores. (Soares, 2009, p. 61)

Nessa perspectiva, a preferência pelas fontes e relatos oficiais identificada por Sigal (1974) e por Gans (2004) fundamenta-se na manutenção de um enquadramento hegemônico que daria preferência ao status quo, marginalizando manifestações contrárias a ele. Este pensamento vai ao encontro do estudo desenvolvido por Soley (1992), que aponta que fontes mais enraizadas no status quo atraem mais a atenção da mídia, ao passo em que:

As mulheres representam mais de metade da população dos EUA, negros compõem mais de $12 \%$, enquanto os sindicatos representam cerca de $20 \%$ da força de trabalho, no entanto, membros desses grupos raramente estão entre as fontes escolhidas pelos jornalistas. (Soley, 1992, p. 17, tradução nossa)

Herbert Gans (2004), também no cenário norte-americano, resume a questão ao afirmar que "as notícias dão suporte à ordem social dos setores da sociedade públicos, empresariais e profissionais, de classe média-alta, meia-idade, masculinos e brancos" (Gans, 2004, p. 61, tradução nossa). Negros e mulheres obtém sucesso na medida em que "se movem para a ordem social existente", e não se apresentam como "separatistas que querem alterá-la".

Em sua defesa da democracia altruísta e oficial, as notícias defendem uma mistura de valores liberais e conservadores. (...) Por outro lado, no seu respeito pela tradição e sua nostalgia de provincianismo e individualismo, as notícias são descaradamente conservadoras, como também é sua defesa da ordem social e sua fé na liderança. Se as notícias tivessem que ser rotuladas 
ideologicamente, elas seriam liberais de direita ou conservadoras de esquerda (Gans, 2004, p. 68, tradução nossa).

Gans (2004), entretanto, evita a visão simplificadora de que as notícias seriam apenas usadas como "apoiadoras complacentes de elites ou estabelecimentos das classes dominantes", mas afirma que elas "encaram a nação e a sociedade através de seu próprio conjunto de valores e com suas próprias concepções de boa ordem social" (Gans, 2004, p.62, tradução nossa), que não são cristalizadas, mas podem mudar com o passar do tempo e com as transformações da sociedade. Não se trata, portanto, de um retorno analítico ao conceito de "paralelismo político" (Lycarião e Maia, 2014).

O pesquisador norte-americano Jim Kuypers (2009), na obra Rhetorical Criticism: Perspectives in Action, enfatiza a pertinência de se aliar a análise de enquadramento (framing analysis) à perspectiva da crítica retórica. Kuypers (2009) vale-se de outros autores, a exemplo de Robert Entman (1993), para estabelecer uma definição para a abrangência do enquadramento midiático. Nesse sentido, o enquadramento se organiza em torno de quatro funções: define problemas, diagnostica causas, promove julgamentos morais e sugere soluções (Entman, 1993, p. 52; Kuypers, 2009, p.185). Na ótica de Kuypers (2009), todavia, o enquadramento midiático constitui um processo no qual os comunicadores, de forma consciente ou não, atuam essencialmente de modo a construir pontos de vista que instigam que os fatos do mundo social sejam interpretados de maneiras particulares a partir de estratégias retóricas.

$\mathrm{O}$ autor compreende o enquadramento com um passo subsequente ao âmbito da agendasetting (McCombs e Shaw, 1972), o qual denomina "agenda estendida" (agendaextension), e propõe a articulação com o universo da retórica:

De forma particular, nós discutimos a concepção de agenda-estendida - a ideia de que a imprensa faz mais do que dizer-nos sobre o que pensar, mas tenta nos dizer como pensar sobre um assunto. Uma versão retórica da análise de enquadramento constitui uma ferramenta que nos permite detectar como este processo de dizer-nos como pensar funciona. $\mathrm{O}$ enquadramento envolve como compreender a forma como a imprensa organiza o contexto por meio do qual o público visualiza as notícias. No coração (do enquadramento) está um processo 
retórico, e por isso eu acredito que a teoria do enquadramento pode ser especialmente frutífera quando adaptada para uma perspectiva retórica. (Kuypers, 2009, 185, tradução nossa).

Além disso, os enquadramentos são geralmente localizados no interior de narrativas mais amplas sobre um assunto ou acontecimento, fazendo delas sua ideia central. Do ponto de vista metodológico, o autor remete à análise comparativa como o cenário ideal para a aplicação dos estudos de enquadramento, uma vez que a ação de enquadrar na mídia "faz algumas ideias mais salientes do que outras, enquanto torna algumas ideias virtualmente invisíveis para a audiência"; e a melhor forma de detectar tal processo faz-se pela condução de um exame que abranja mais do que uma simples notícia (Kuypers, 2009, p. 185, tradução nossa).

\section{Considerações finais: o enquadramento hegemônico nas estratégias retóricas de Veja e IstoÉ}

O cruzamento dos dados empíricos extraídos das edições de janeiro e dezembro de 2015 das revistas Veja e IstoÉ com as reflexões de natureza teórico-conceitual oriundas, sobretudo, da perspectiva teórico-metodológica da framing analysis em interface com análise retórica (Kuypers, 2009), permite abstrair considerações e constatações a respeito das estratégias de construção de um enquadramento peculiar sobre o primeiro ano do segundo mandato da presidenta Dilma Rousseff. Nos termos de Citelli (2003, p.8), cabe à retórica "mostrar o modo de constituir as palavras visando convencer o receptor acerca de dada verdade" - horizonte que dialoga com o vértice de Gitlin (2003, p. 49-51, tradução nossa), segundo o qual "os meios de comunicação são holofotes móveis e não espelhos passivos da sociedade", direcionando seus "feixes de luz" para dar destaque a alguns acontecimentos em detrimento de outros.

Ao retomar o conceito de enquadramento noticioso como "padrões persistentes de cognição, interpretação e apresentação, de seleção, ênfase e exclusão, pelos quais manipuladores de símbolos rotineiramente organizam discursos" (Gitlin, 2003, p. 7, 
tradução nossa), reconhece-se que os enquadramentos são inerentes ao processo de produção das notícias. Desse modo, sob nenhum risco de recair-se numa espécie de "realismo ingênuo" (Gomes, 2009), é ponto pacífico a compreensão de que uma revista semanal de padrão industrial - a exemplo de Veja ou IstoÉ - possui um número determinado de páginas impressas, desenvolvendo inevitavelmente processos de seleção para definir o que será ou não publicado e de que maneira o conteúdo será apresentado. Esse processo inclui diversas variáveis e começa com a definição adotada pelos próprios meios de comunicação sobre o que é ou não notícia - ou seja, os critérios noticiosos escolhidos.

Outro fator determinante é a escolha das fontes ouvidas pelos jornalistas, visto que "para o repórter, em suma, a maioria das notícias constitui não o que aconteceu, mas o que alguém diz que aconteceu, tornando a escolha de fontes crucial" (Sigal, 1974, p. 69, tradução nossa). Embora auxiliem no processo de padronização do conteúdo dos veículos (Sigal, 1974), tais elementos, entretanto, dependem também de outras variáveis, como os recursos disponíveis para as coberturas, o formato do produto final e as posições ideológicas adotadas pelas corporações de mídia. A padronização, os estereótipos e a rotina de julgamentos praticada nas redações - isto é, a sistematização e a rotinização do processo (Tuchman, 1973) - fazem parte, segundo Lippmann (2010), de um modelo de jornalismo industrial que tem como objetivos principais a economia de tempo e esforço (Lippmann, 2010, p. 300), sendo já tão cristalizados que muitas vezes nem mesmo os próprios jornalistas os identificam de maneira consciente.

Quanto à escolha das fontes, na perspectiva específica da análise aqui desenvolvida, transparecem-se algumas das principais estratégias retóricas adotadas pelas revistas semanais: os resultados encontrados na pesquisa, além de todos os dados pormenorizados nos itens anteriores, respaldam no cenário brasileiro as conclusões oriundas dos estudos de Lawrence Soley (1992) sobre a constituição de um padrão hegemônico das fontes no jornalismo norte-americano. De todas as fontes presentes nas dezesseis matérias selecionadas, apenas $10 \%$ eram mulheres, $6 \%$ eram negros e menos de $2 \%$ representavam grupos sindicais ou associações de trabalhadores. Merece destaque, todavia, conforme demonstra a análise dos canais de informação, o fato peculiar de a própria presidenta Dilma Rousseff, principal personagem da análise desenvolvida, não ter sido ouvida 
diretamente pelos jornalistas em nenhuma ocorrência, sendo suas falas resumidas a trechos de comunicados oficiais ou até mesmo sem ter a procedência identificada. $\mathrm{O}$ uso de fontes não identificadas ou cujos canais de comunicação não ficam explícitos na matéria, também foram práticas recorrentes em ambas as revistas no período estudado.

Para além de identificar a utilização de recursos como o silenciamento de atores políticos (sendo o mais explícito o da própria personagem principal da cobertura, a presidenta Dilma Rousseff) e da utilização de fontes não identificadas ("assessores próximos a Dilma", "colaborador próximo ao parlamentar") a análise evidencia também o uso recorrente de figuras retóricas de construção textual como a simplificação, a personificação, a amplificação e a dramatização. Levando-se em conta todas as características apresentadas, reconhece-se que os dois veículos, apesar de considerados concorrentes no segmento das revistas semanais, constroem um enquadramento bem semelhante na elaboração de seus produtos. Como os enquadramentos são também interpretados como instrumentos de poder (Gitlin, 2003; Kuypers, 2009; Porto, 2002) e adotando-se como dado representativo o público numericamente relevante que ambas as revistas atingem, identifica-se uma categoria de "enquadramento hegemônico" (Gitlin, 2003) sendo utilizada pelos dois veículos comunicacionais.

Isso se confirma na medida em que as publicações expõem seus pontos de vista sem conceder margens a opiniões contrárias, o que, na ótica da retórica, constitui uma "modalidade discursiva autoritária", aquela que se fecha à polifonia, à polissemia e se manifesta como circunlóquio, "sem qualquer possibilidade de interferir e modificar aquilo que está sendo dito" (Citelli, 2003, p.39). Os periódicos também utilizam os argumentos da "objetividade" e da "isenção" para, como afirma Schudson (2010), "camuflar", num discurso de autolegitimação, o enquadramento temático e ideológico que os meios exercem sobre seus públicos.

Tais estratégias retóricas, evidentemente, não contribuem para a constituição e para o amadurecimento do debate democrático no país. Nesse contexto, as constatações oriundas do estudo seguem ao encontro da concepção de Gitlin (2003, p. 264) de que o trabalho da hegemonia, num vértice gramsciano, "consiste em impor suposições padronizadas sobre eventos e condições" que são encobertas nas entrelinhas das notícias predominantes. 
Mesmo sem valer-se da lógica do paralelismo político, o processo de impeachment levado a cabo meses após o recorte empírico aqui delineado coloca em evidência, dentre outros fatores, a articulação do vetor midiático no processo de construção de uma retórica mais ampla que ajudou a inviabilizar o mandato de Dilma Rousseff. Trata-se, entretanto, de tema para outra reflexão.

\section{Referências}

ANER. Circulação Revistas Semanais - 2013 x 2014 (Jan a Set). Disponível em: <http://aner.org.br/dados-de-mercado/circulacao/>. Acesso em 01 mar. 2016.

AZEVEDO, Fernando Antonio. As revistas semanais e a cobertura das eleições presidenciais de 2002. In: Anais da VII BRASA - Brazilian Studies Association, Rio de Janeiro, 2004.

BRASIL. Senado Federal. Sentença de julgamento do impeachment de Dilma Rousseff. Relator: Ministro Ricardo Lewandowski. Brasília, 31 de agosto de 2016. Disponível em:

$<$ http://www12.senado.leg.br/noticias/arquivos/2016/08/31/veja-a-sentenca-de-impeachmentcontra-dilma-rousseff >. Acesso em: 07 mar. 2017.

CITELLI, Adilson. Linguagem e persuasão. São Paulo: Ática, 2003.

ENTMAN, Robert. M. Framing: towards clarification of a fractured paradigm. Journal Communication, v. 43, n.4, p.51-58, 1993.

GANS, Herbert J. Deciding What's News: A Study of CBS Evening News, NBC Nightly News, Newsweek, and Time. Illinois: Northwestern University Press, 2004.

GITLIN, Todd. The Whole World Is Watching: Mass Media in the Making and Unmaking of the New Left. California: University of California Press, 2003.

GOFFMAN, Erving. Os quadros da experiência social: Uma perspectiva de análise. Petrópolis: Editora Vozes, 2012.

GOMES, Wilson. Jornalismo Fatos e Interesses: Ensaios de teoria do jornalismo. Florianópolis: Insular, 2009.

KUYPERS, Jim A. Framing analysis. In: KUYPERS, Jim A. (Org.). Rhetorical Criticism: perspectives in action. New York: Lexington Books, 2009.

LAGE, Nilson. A reportagem: Teoria e técnica de entrevista e pesquisa jornalística. Rio de Janeiro: Record, 2005.

LIPPMANN, Walter. Opinião Pública. 2. ed. Petrópolis: Editora Vozes, 2010.

LYCARIÃO, Diógenes; MAIA, Rousiley. A COP-15 sob holofotes midiáticos: modos e níveis de intervenção política do jornalismo no sistema de mídia brasileiro. In: Anais do XXIII Encontro 
Anual da Associação Nacional dos Programas de Pós-Graduação em Comunicação (COMPÓS), Universidade Federal do Pará, 2014.

MCCOMBS, Maxwell E.; SHAW, Donald L. The Agenda-Setting functions of the mass media. Public Opinion Quarterly, n. 36, p.176-187, 1972.

MIGUEL, Luis Felipe; BIROLI, Flávia. Gênero e política no jornalismo brasileiro. Revista Famecos, v. 15, n. 36, p. 24-39, 2008.

PORTO, Mauro P. Enquadramentos da Mídia e Política. In: Anais do XXVI Encontro Anual da Associação Nacional de Pós-Graduação e Pesquisa em Ciências Sociais (ANPOCS), Caxambu (MG), 2002.

PRADO, José Luiz Aidar. O leitor infiel diante dos mapas da mídia semanal performativa. Fronteiras-estudos midiáticos, v. 7, n. 1, p. 39-46, 2005.

SCHUDSON, Michael. Descobrindo a Notícia: Uma história social dos jornais nos Estados Unidos. Petrópolis: Editora Vozes, 2010.

SHOEMAKER, Pamela J. e COHEN, Akiba. News around the world: Practitioners, Content, and the Public. New York: Routledge, 2006.

SIGAL, Leon V. Reporters and Officials: The Organization and Politics of Newsmaking. 2 ed. Estados Unidos: D.C. Heath and Company, 1974.

SILVA, Gislene. Para pensar a noticiabilidade. Revista Estudos em Jornalismo e Mídia. Universidade Federal de Santa Catarina, v. 2, n. 1, p. 95-107, 2005.

SOARES, Murilo Cesar. Veja e a construção do CR-P nas eleições presidenciais de 1998. In: Anais do VIII Encontro Anual da Associação Nacional de Programas de Pós-Graduação em Comunicação (Compós), Belo Horizonte, 1999.

SOARES, Murilo César. Representações, Jornalismo e a Esfera Pública Democrática. São Paulo: Cultura Acadêmica, 2009.

SOLEY, Lawrence C. The News Shapers: The Sources Who Explain the News. New York, Westport, London: Praeger Publishers, 1992.

TRAQUINA, Nelson. Teorias do Jornalismo: A tribo jornalística - uma comunidade interpretativa transnacional, 2. ed. Florianópolis: Insular, 2008.

TUCHMAN, Gaye. Making news by doing work: routinizing the unexpected. American Journal of Sociology, v.79, n.1, p. 110-131, 1973.

WOLF, Mauro. Teorias da comunicação. 8.ed. Lisboa: Editorial Presenç 


\section{Os Autores}

Marcos Paulo da Silva é professor do Programa de Pós-Graduação em Comunicação e do Curso de Jornalismo da Universidade Federal de Mato Grosso do Sul (UFMS). Doutor em Comunicação Social pela Universidade Metodista de São Paulo (UMESP), com estágio de doutorado-sanduíche na Syracuse University (Nova lorque, Estados Unidos).

marcos.paulo@ufms.br

Raquel de Souza Jeronymo é mestranda do Programa de Pós-Graduação em Comunicação da Universidade Federal de Mato Grosso do Sul (UFMS). Bolsista da Coordenação de Aperfeiçoamento de Pessoal de Nível Superior (CAPES). Graduada em Comunicação Social Habilitação em Jornalismo pela UFMS.

raquels.jeronymo@gmail.com 